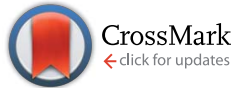

Cite this: RSC Adv., 2017, 7, 10575

Received 16th January 2017

Accepted 2nd February 2017

DOI: $10.1039 / \mathrm{c} 7 \mathrm{ra00656j}$

rsc.li/rsc-advances

\section{Preparation of protic ionic liquids containing cyclic oligosiloxane frameworks}

\author{
T. Hirohara, ${ }^{a}$ T. Kai, ${ }^{\text {b }}$ J. Ohshita ${ }^{\text {b }}$ and Y. Kaneko*a
}

Protic ionic liquids (PILs) containing cyclic oligosiloxanes with ammonium side-chain groups (Am-CyS-IL and $2 \mathrm{Am}$-CyS-IL) were successfully prepared by the hydrolytic condensation of 3-aminopropyldimethoxymethylsilane and 3-(2-aminoethylamino)propyldimethoxymethylsilane, respectively, in a water/methanol $(1: 19 \mathrm{v} / \mathrm{v})$ mixed solution of bis(trifluoromethanesulfonyl)imide $\left(\mathrm{HNTf}_{2}\right)$. The differential scanning calorimetry (DSC) curves of Am-CyS-IL and 2Am-CyS-IL exhibited baseline shifts attributable to glass transition temperatures $\left(T_{\mathrm{g}}\right)$ of $-2{ }^{\circ} \mathrm{C}$ and $9{ }^{\circ} \mathrm{C}$, respectively, and endothermic peaks at their melting temperatures $\left(T_{\mathrm{m}}\right)$ were not detected for both compounds, indicating their amorphous structures. In addition, fluidity was visually observed for each compound at $\sim 35^{\circ} \mathrm{C}$ and $\sim 45{ }^{\circ} \mathrm{C}$, respectively. On the basis of these results, we concluded that Am-CyS-IL and 2Am-CyS-IL were PILs. To investigate the influence of the kind of siloxane framework on the nature of the ionic liquid, we prepared polyhedral oligomeric silsesquioxanes (POSSs) containing the same side-chain groups and counteranions (Am-POSS and 2Am-POSS) from 3-aminopropyltrimethoxysilane and 3-(2-aminoethylamino)propyltrimethoxysilane, respectively, using an $\mathrm{HNTf}_{2}$ catalyst. Am-POSS had a $T_{\mathrm{g}}$ of $15^{\circ} \mathrm{C}$ and a $T_{\mathrm{m}}$ of $193{ }^{\circ} \mathrm{C}$, and $2 \mathrm{Am}$-POSS had a $T_{\mathrm{g}}$ of $32{ }^{\circ} \mathrm{C}$ and a $T_{\mathrm{m}}$ of $208^{\circ} \mathrm{C}$, which were estimated by DSC analyses. Furthermore, fluidity was not observed below $150{ }^{\circ} \mathrm{C}$ for both compounds, indicating that these POSS compounds were not PILs. These results suggest that the cyclic oligosiloxane frameworks are an important factor for the preparation of siloxane-based PILs exhibiting fluidity at low temperature. In addition, the present PILs containing cyclic oligosiloxane frameworks exhibited relatively high decomposition temperatures ( $T_{\mathrm{d}}$; Am-CyS-IL: $T_{\mathrm{d} 5}=$ $351^{\circ} \mathrm{C}$ and $T_{\mathrm{d} 10}=362{ }^{\circ} \mathrm{C}, 2 \mathrm{Am}-\mathrm{CyS}-\mathrm{IL}: T_{\mathrm{d} 5}=294^{\circ} \mathrm{C}$ and $T_{\mathrm{d} 10}=309^{\circ} \mathrm{C}$ ).

\section{Introduction}

Ionic liquids (ILs) are generally defined as molten salts below $100^{\circ} \mathrm{C}$ or $150^{\circ} \mathrm{C}$. ILs are classified as aprotic ILs (AILs) or protic ILs (PILs) depending on the absence or presence of protons. PILs are prepared by a simple neutralization (proton transfer) reaction between a Brønsted acid and a Brønsted base., ${ }^{1,2}$ Therefore, they have the advantages of being easier to prepare and cheaper compared with AILs. So far, PILs have been widely studied due to their remarkable potential as electrolytes for fuel cells, ${ }^{3}$ lithium-ion batteries ${ }^{4}$ and capacitors, ${ }^{5}$ as biomass extraction solvents, ${ }^{6}$ and for carbon dioxide captures. ${ }^{7,8}$ In particular, because PILs have relatively good thermal stability, they are expected to be applied as thermostable proton conductors (solid electrolytes) for fuel cells. However, the decomposition temperatures $\left(T_{\mathrm{d}}\right)$ of PILs on pyrolysis are generally lower than those of AILs because of proton transfer

${ }^{a}$ Graduate School of Science and Engineering, Kagoshima University, 1-21-40 Korimoto, Kagoshima 890-0065, Japan. E-mail: ykaneko@eng.kagoshima-u.ac.jp; Fax: +8199285 7794; Tel: +81992857794

${ }^{b}$ Graduate School of Engineering, Hiroshima University, Higashi-Hiroshima, Hiroshima 739-8527, Japan from the cation back to the anion to reform the original acid and base neutral species. ${ }^{1}$

So far, in the field of AILs, ILs containing siloxane frameworks have been reported.9-14 Siloxane compounds exhibit excellent thermal stability due to the high binding energy of their Si-O-Si linkages. An AIL containing polyhedral oligomeric silsesquioxane (POSS), a siloxane framework, was first prepared by Chujo, Tanaka, and co-worker. ${ }^{9}$ This POSS-AIL contained carboxylate anion side chains and imidazolium cations as counterions. Zhang et al. have also reported the preparation of an AIL containing POSS with imidazolium cations side chains and dodecyl sulfate anions as counterions. ${ }^{10}$ Meanwhile, we prepared a highly thermostable POSS-AIL containing imidazolium cationic side-chains and bis(trifluoromethanesulfonyl) imide $\left(\mathrm{NTf}_{2}\right)$ anions as counterions by a simple hydrolytic condensation method. ${ }^{11}$ In addition, AILs containing randomly structured oligomeric silsesquioxanes with imidazolium ${ }^{11}$ and quaternary ammonium ${ }^{12}$ side-chain groups were also prepared. More recently, a room-temperature POSS-AIL containing two types of cationic side-chain groups, i.e. imidazolium and quaternary ammonium groups, and $\mathrm{NTf}_{2}$ anions as counterions was prepared by a similar hydrolytic condensation method. ${ }^{13}$ Furthermore, as an example of AILs containing other types of 
siloxane frameworks, we prepared imidazolium salt type AILs containing cyclic siloxanes. ${ }^{\mathbf{1 4}}$ In these siloxane-based AILs prepared by us, the use of a superacid catalyst is essential for structural control and indicating IL nature. The $T_{\mathrm{d}}$ values of the aforementioned AILs containing siloxane frameworks were higher than those of AILs with side-chain structures of the corresponding siloxane-based AILs. Therefore, PILs containing siloxane frameworks are expected to exhibit higher thermal stability. However, to the best of our knowledge, the preparation of PILs containing siloxane frameworks has not yet been reported.

To successfully prepare such siloxane-based PILs, we referred to our previous study of the facile preparation of a single-structured cyclic tetrasiloxane containing ammonium groups by the hydrolytic condensation of 3-aminopropyldiethoxymethylsilane using aqueous superacid trifluoromethanesulfonic acid (HOTf) as a catalyst. ${ }^{15}$ However, this cyclic tetrasiloxane was not an $\mathrm{IL}$, i.e. its melting temperature $\left(T_{\mathrm{m}}\right)$ is $\mathrm{ca} .310{ }^{\circ} \mathrm{C}$. In general, it has been reported that $T_{\mathrm{m}}$ and/or flow temperatures of ILs containing $\mathrm{NTf}_{2}$ anions are lower than those containing OTf anions with the same cationic species. ${ }^{\mathbf{1 4 , 1 6}}$

In this study, when the hydrolytic condensation of dialkoxysilanes containing primary and/or secondary amino groups, such as 3-aminopropyldimethoxymethylsilane (APDMMS) and 3-(2aminoethylamino)propyldimethoxymethylsilane (AEAPDMMS), were investigated using superacid $\mathrm{HNTf}_{2}$ as a catalyst, we found that PILs containing cyclic oligosiloxane frameworks were successfully prepared. Here we report the preparation, characterizations and thermal properties of these PILs, and a comparison of the properties with POSSs containing the same side-chain groups and counterions.

\section{Experimental}

\section{Materials}

APDMMS, AEAPDMMS, 3-aminopropyltrimethoxysilane (APTMS) and 3-(2-aminoethylamino)propyltrimethoxysilane (AEAPTMS) were purchased from Tokyo Chemical Industry Co., Ltd. (Japan). Other reagents and solvents were purchased from Wako Pure Chemical Industries, Ltd. (Japan). All reagents and solvents were used without further purification.

\section{Preparation of PILs containing cyclic oligosiloxane with one ammonium group per repeating unit (Am-CyS-IL)}

A water/methanol $(1: 19 \mathrm{v} / \mathrm{v})$ mixed solution of $\mathrm{HNTf}_{2}(0.5 \mathrm{~mol}$ $\mathrm{L}^{-1}, 15 \mathrm{~mL}, 7.5 \mathrm{mmol}$ ) was added to APDMMS (purity: 97\%, $0.505 \mathrm{~g}, 3.0 \mathrm{mmol}$ ) with stirring at room temperature. After the resulting solution was further stirred for $2 \mathrm{~h}$, this solution was heated at $\sim 60{ }^{\circ} \mathrm{C}$ in an open container until the solvent evaporated. Subsequently, the resulting viscous product was maintained at $100{ }^{\circ} \mathrm{C}$ for $\sim 2 \mathrm{~h}$, dissolved in methanol $(1 \mathrm{~mL})$ at room temperature, and then this methanol solution was poured into chloroform (30 mL). The chloroform-insoluble part was isolated by decantation, washed with chloroform $(\sim 30 \mathrm{~mL} \times 3)$, and then dried by heating at $150{ }^{\circ} \mathrm{C}$ for $\sim 10 \mathrm{~h}$ to yield $1.019 \mathrm{~g}$ of a viscous product (Am-CyS-IL; yield, $\sim 85 \%$; the ideal chemical formula of one repeating unit of the product
$\left[\mathrm{CH}_{3} \mathrm{SiO}\left(\mathrm{CH}_{2}\right)_{3} \mathrm{NH}_{3} \cdot\left(\mathrm{CF}_{3} \mathrm{SO}_{2}\right)_{2} \mathrm{~N}, \mathrm{FW}=398.4\right]$ was used for this determination). ${ }^{1} \mathrm{H}$ NMR (400 MHz, DMSO- $\left.d_{6}\right): \delta 7.80-7.43(3 \mathrm{H}$, br, $\left.-\mathrm{NH}_{3}\right), \delta 2.83-2.64\left(2 \mathrm{H}, \mathrm{br},-\mathrm{CH}_{2} \mathrm{NH}_{3}\right), \delta 1.61-1.41(2 \mathrm{H}, \mathrm{br}$, $\left.-\mathrm{SiCH}_{2} \mathrm{CH}_{2} \mathrm{CH}_{2} \mathrm{NH}_{3}\right), \delta$ 0.63-0.37 (2H, br, $\left.-\mathrm{SiCH}_{2}-\right), \delta 0.19$ to $-0.03\left(3 \mathrm{H}, \mathrm{br},-\mathrm{SiCH}_{3}\right) .{ }^{29} \mathrm{Si} \mathrm{NMR}\left(79.5 \mathrm{MHz}, \mathrm{DMSO}-d_{6}\right): \delta-19.3$ to $-19.8\left(\mathrm{D}^{2}\right.$, cyclic tetramer $), \delta-21.6$ to $-21.9\left(\mathrm{D}^{2}\right.$, cyclic pentamer), $\delta-22.2$ to $-22.5\left(\mathrm{D}^{2}\right.$, cyclic hexamer).

\section{Preparation of PILs containing cyclic oligosiloxane with two ammonium groups per repeating unit (2Am-CyS-IL)}

A water/methanol $(1: 19 \mathrm{v} / \mathrm{v})$ mixed solution of $\operatorname{HNTf}_{2}(0.5 \mathrm{~mol}$ $\mathrm{L}^{-1}, 30 \mathrm{~mL}, 15 \mathrm{mmol}$ ) was added to AEAPDMMS (purity: 97\%, $0.638 \mathrm{~g}, 3.0 \mathrm{mmol}$ ) with stirring at room temperature. The subsequent procedures were the same as those described above for the preparation of Am-CyS-IL, and $1.896 \mathrm{~g}$ of a viscous product (2Am-CyS-IL) was obtained (yield, $\sim 87 \%$; the ideal chemical formula of one repeating unit of the product $\left[\mathrm{CH}_{3}\right.$ $\left.\mathrm{SiO}\left(\mathrm{CH}_{2}\right)_{3} \mathrm{NH}_{2}\left(\mathrm{CH}_{2}\right)_{2} \mathrm{NH}_{3} \cdot 2\left(\mathrm{CF}_{3} \mathrm{SO}_{2}\right)_{2} \mathrm{~N}, \mathrm{FW}=722.7\right]$ was used for this determination). ${ }^{1} \mathrm{H}$ NMR (400 MHz, DMSO- $\left.d_{6}\right): \delta 8.56-$ $8.14\left(2 \mathrm{H}, \mathrm{br},-\mathrm{NH}_{2} \mathrm{CH}_{2} \mathrm{CH}_{2} \mathrm{NH}_{3}\right), \delta$ 7.99-7.60 (3H, br, $-\mathrm{NH}_{2}-$ $\mathrm{CH}_{2} \mathrm{CH}_{2} \mathrm{NH}_{3}$ ), $\delta$ 3.20-2.97 (4H, br, $-\mathrm{NH}_{2} \mathrm{CH}_{2} \mathrm{CH}_{2} \mathrm{NH}_{3}$ ), $\delta$ 2.97$2.75\left(2 \mathrm{H}, \mathrm{br},-\mathrm{SiCH}_{2} \mathrm{CH}_{2} \mathrm{CH}_{2} \mathrm{NH}_{2}-\right), \delta$ 1.69-1.38 (2H, br, $\left.-\mathrm{SiCH}_{2} \mathrm{CH}_{2} \mathrm{CH}_{2} \mathrm{NH}_{2}-\right), \delta 0.70-0.36\left(2 \mathrm{H}, \mathrm{br},-\mathrm{SiCH}_{2}-\right), \delta 0.27$ to $-0.01\left(3 \mathrm{H}, \mathrm{br},-\mathrm{SiCH}_{3}\right) .{ }^{29} \mathrm{Si} \mathrm{NMR}\left(79.5 \mathrm{MHz}, \mathrm{DMSO}-d_{6}\right): \delta-19.1$ to $-20.1\left(\mathrm{D}^{2}\right.$, cyclic tetramer $), \delta-21.3$ to $-21.8\left(\mathrm{D}^{2}\right.$, cyclic pentamer), $\delta-22.1$ to $-22.3\left(\mathrm{D}^{2}\right.$, cyclic hexamer).

\section{Preparation of POSS with one ammonium group per repeating} unit (Am-POSS)

An aqueous $\mathrm{HNTf}_{2}$ solution $\left(0.5 \mathrm{~mol} \mathrm{~L}^{-1}, 15 \mathrm{~mL}, 7.5 \mathrm{mmol}\right)$ was added to APTMS (purity: $96 \%, 0.560 \mathrm{~g}, 3.0 \mathrm{mmol}$ ) with stirring at room temperature. The subsequent procedures were the same as those described above for the preparation of Am-CyS-IL, and $1.150 \mathrm{~g}$ of a solid substance (Am-POSS) was obtained (yield, $\sim 98 \%$; the ideal chemical formula of one repeating unit of the product $\left[\mathrm{SiO}_{1.5}\left(\mathrm{CH}_{2}\right)_{3} \mathrm{NH}_{3} \cdot\left(\mathrm{CF}_{3} \mathrm{SO}_{2}\right)_{2} \mathrm{~N}, \mathrm{FW}=391.4\right]$ was used for this determination). ${ }^{1} \mathrm{H}$ NMR (400 MHz, DMSO- $\left.d_{6}\right): \delta 7.70-$ $7.46\left(3 \mathrm{H}, \mathrm{br},-\mathrm{NH}_{3}\right), \delta 2.84-2.63\left(2 \mathrm{H}, \mathrm{br},-\mathrm{CH}_{2} \mathrm{NH}_{3}\right), \delta 1.63-1.40$ $\left(2 \mathrm{H}, \mathrm{br},-\mathrm{SiCH}_{2} \mathrm{CH}_{2} \mathrm{CH}_{2} \mathrm{NH}_{3}\right), \delta 0.74-0.52\left(2 \mathrm{H}, \mathrm{br},-\mathrm{SiCH}_{2}-\right) .{ }^{29} \mathrm{Si}$ NMR (79.5 MHz, DMSO- $\left.d_{6}\right): \delta-66.5\left(\mathrm{~T}_{8}\right), \delta-68.5\left(\mathrm{~T}_{10}\right)$.

\section{Preparation of POSS with two ammonium groups per repeating unit (2Am-POSS)}

A aqueous $\mathrm{HNTf}_{2}$ solution $\left(0.5 \mathrm{~mol} \mathrm{~L}{ }^{-1}, 30 \mathrm{~mL}, 15 \mathrm{mmol}\right)$ was added to AEAPTMS (purity: 95\%, $0.702 \mathrm{~g}, 3.0 \mathrm{mmol}$ ) with stirring at room temperature. The subsequent procedures were the same as those described above for the preparation of Am-CySIL, and $2.110 \mathrm{~g}$ of a solid substance (2Am-POSS) was obtained (yield, $\sim 98 \%$; the ideal chemical formula of one repeating unit of the product $\left[\mathrm{SiO}_{1.5}\left(\mathrm{CH}_{2}\right)_{3} \mathrm{NH}_{2}\left(\mathrm{CH}_{2}\right)_{2} \mathrm{NH}_{3} \cdot 2\left(\mathrm{CF}_{3} \mathrm{SO}_{2}\right)_{2} \mathrm{~N}, \mathrm{FW}=\right.$ 715.6] was used for this determination). ${ }^{1} \mathrm{H}$ NMR $(400 \mathrm{MHz}$, DMSO- $\left.d_{6}\right): \delta 8.48-8.23\left(2 \mathrm{H}, \mathrm{br},-\mathrm{NH}_{2} \mathrm{CH}_{2} \mathrm{CH}_{2} \mathrm{NH}_{3}\right), \delta$ 7.96-7.69 $\left(3 \mathrm{H}, \mathrm{br},-\mathrm{NH}_{2} \mathrm{CH}_{2} \mathrm{CH}_{2} \mathrm{NH}_{3}\right), \delta 3.20-2.91\left(4 \mathrm{H}, \mathrm{br},-\mathrm{NH}_{2} \mathrm{CH}_{2} \mathrm{CH}_{2}-\right.$ $\mathrm{NH}_{3}$ ), $\delta$ 2.91-2.68 (2H, br, $\left.-\mathrm{SiCH}_{2} \mathrm{CH}_{2} \mathrm{CH}_{2} \mathrm{NH}_{2}-\right)$, $\delta$ 1.69-1.33 $\left(2 \mathrm{H}, \mathrm{br},-\mathrm{SiCH}_{2} \mathrm{CH}_{2} \mathrm{CH}_{2} \mathrm{NH}_{2}-\right), \delta 0.78-0.40\left(2 \mathrm{H}, \mathrm{br},-\mathrm{SiCH}_{2}-\right)$. ${ }^{29} \mathrm{Si} \mathrm{NMR}\left(79.5 \mathrm{MHz}, \mathrm{DMSO}-d_{6}\right): \delta-67.3\left(\mathrm{~T}_{8}\right), \delta-69.4\left(\mathrm{~T}_{10}\right)$. 


\section{Measurements}

${ }^{1} \mathrm{H}$ and ${ }^{29} \mathrm{Si}$ NMR spectra were recorded using a JEOL ECX-400 spectrometer (JEOL Ltd.). The atomic ratios of $\mathrm{Si}: \mathrm{S}$ in the products were confirmed by energy-dispersive X-ray (EDX) analyses using an XL30 scanning electron microscope (FEI Co.). Matrix-assisted laser desorption ionization time-of-flight mass spectral (MALDI-TOF MS) analyses of the products were performed using a Shimadzu Voyager Biospectrometry Workstation Ver. 5.1 (SHIMADZU Co.) positive ion mode with 2,5dihydroxybenzoic acid (DHB) as the matrix. Attenuated total reflectance infrared (ATR-IR) spectra were recorded using a JASCO FTIR-4200 spectrometer (JASCO Co.). Differential scanning calorimetry (DSC) analyses were performed using a DSC-60 Plus (SHIMADZU Co.). The sample was placed in an aluminium capsule and cooled to $-140{ }^{\circ} \mathrm{C}$ at a rate of $20{ }^{\circ} \mathrm{C}$ $\mathrm{min}^{-1}$ under a nitrogen flow $\left(50 \mathrm{~mL} \mathrm{~min}^{-1}\right)$, and then heated from $-140{ }^{\circ} \mathrm{C}$ to $250{ }^{\circ} \mathrm{C}$ at the same rate. Glass transition temperatures $\left(T_{\mathrm{g}}\right)$ and $T_{\mathrm{m}}$ were determined as the onset of baseline shifts and as the tops of endothermic peaks, respectively, in the third set of curves (from $-140{ }^{\circ} \mathrm{C}$ to $250{ }^{\circ} \mathrm{C}$ at a rate of $20^{\circ} \mathrm{C} \mathrm{min}^{-1}$ ) to eliminate the heat histories of the samples. $\mathrm{X}$ ray diffraction (XRD) patterns were recorded at a scanning speed of $2 \theta=6.6^{\circ} \mathrm{min}^{-1}$ using an X'Pert Pro diffractometer (PANalytical) with Ni-filtered $\mathrm{Cu} \mathrm{K} \alpha$ radiation $(0.15418 \mathrm{~nm})$. Thermogravimetric analyses (TGA) were performed on an Exstar TG/DTA6200 (Seiko Instruments) at a heating rate of $10{ }^{\circ} \mathrm{C}$ $\mathrm{min}^{-1}$ up to $1000^{\circ} \mathrm{C}$ under a nitrogen flow $\left(250 \mathrm{~mL} \mathrm{~min}^{-1}\right)$. The decomposition temperatures were determined from the $5 \%$ $\left(T_{\mathrm{d} 5}\right)$ and $10 \%\left(T_{\mathrm{d} 10}\right)$ weight losses.

\section{Results and discussion}

\section{Preparation and characterizations of Am-CyS-IL and 2Am-CyS-} IL

A PIL containing a cyclic oligosiloxane with one ammonium group per repeating unit, Am-CyS-IL, was prepared according to the following procedure (Scheme 1a): APDMMS was stirred in a water/methanol $(1: 19 \mathrm{v} / \mathrm{v})$ mixed solution of $\mathrm{HNTf}_{2}(0.5 \mathrm{~mol}$ $\mathrm{L}^{-1}$ ) at room temperature for $2 \mathrm{~h}$. Here, an excess amount of $\mathrm{HNTf}_{2}$ was required (the feed molar ratio of $\mathrm{HNTf}_{2} /$ APDMMS was 2.5). The resulting solution was heated at $c a .60{ }^{\circ} \mathrm{C}$ in an open container until the solvent evaporated. The resulting

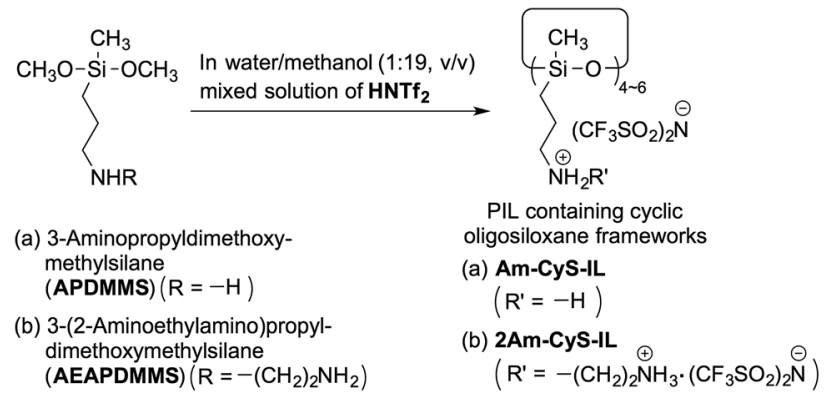

Scheme 1 Preparation of PILs containing cyclic oligosiloxane frameworks: (a) Am-CyS-IL and (b) 2Am-CyS-IL.

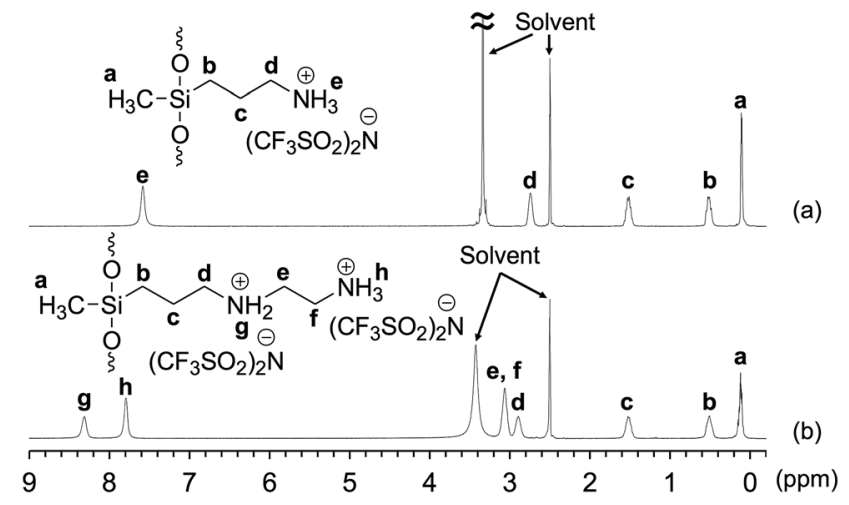

Fig. $1{ }^{1} \mathrm{H}$ NMR spectra of (a) Am-CyS-IL and (b) 2Am-CyS-IL in DMSO $-d_{6}$. Chemical shifts were referenced to DMSO $(\delta 2.5)$.

crude product was further heated at $100{ }^{\circ} \mathrm{C}$ for $2 \mathrm{~h}$, washed with chloroform, and then dried at $150{ }^{\circ} \mathrm{C}$ for $\sim 10$ h to obtain AmCyS-IL. Am-CyS-IL was soluble in high-polarity solvents, such as water, methanol and acetone, but insoluble in low-polarity solvents, such as chloroform, toluene and hexane.

The ${ }^{1} \mathrm{H}$ NMR spectrum of Am-CyS-IL in DMSO- $d_{6}$ exhibited signals attributable to 3-aminopropyl and methyl groups, but signals due to the methoxy groups of APDMMS were not observed (Fig. 1a), indicating that the APDMMS reagent was not present in the product. The EDX pattern of Am-CyS-IL revealed that the $\mathrm{Si}$ : $\mathrm{S}$ atomic ratio was $c a .1 .00: 1.99$, indicating that the molar ratio of the ammonium cation to the $\mathrm{NTf}_{2}$ anion in AmCyS-IL was $c a$. $1: 1$ (Fig. 2a). In the MALDI-TOF MS analysis of Am-CyS-IL, several peaks were observed that corresponded to the masses of cyclic siloxane tetramer, pentamer and hexamer (Fig. 3a). The ${ }^{29}$ Si NMR spectrum of Am-CyS-IL in DMSO- $d_{6}$ at $40{ }^{\circ} \mathrm{C}$ showed three multiple signals in the $\mathrm{D}^{2}$ region $(-19.3$ to $-19.8 \mathrm{ppm}$ for cyclic tetrasiloxane, -21.6 to $-21.9 \mathrm{ppm}$ for cyclic pentasiloxane, and -22.2 to $-22.5 \mathrm{ppm}$ for cyclic hexasiloxane) and no signals in the $\mathrm{D}^{1}$ region at $c a$. $-15 \mathrm{ppm}$ (Fig. 4a). Furthermore, the aforementioned ${ }^{1} \mathrm{H}$ NMR spectrum contained multiple signals, a, attributable to methyl groups at 0.20 to -0.01 ppm (Fig. 1a). These results indicate that Am-CySIL was a mixture of cyclic tetra-, penta-, and hexasiloxanes, with some stereoisomers.

A PIL containing a cyclic oligosiloxane with two ammonium groups per repeating unit, 2Am-CyS-IL, was prepared using almost the same procedure as that of Am-CyS-IL but using

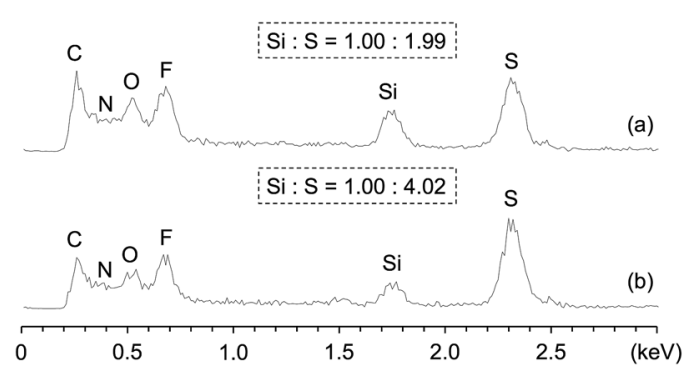

Fig. 2 EDX patterns of (a) Am-CyS-IL and (b) 2Am-CyS-IL. 

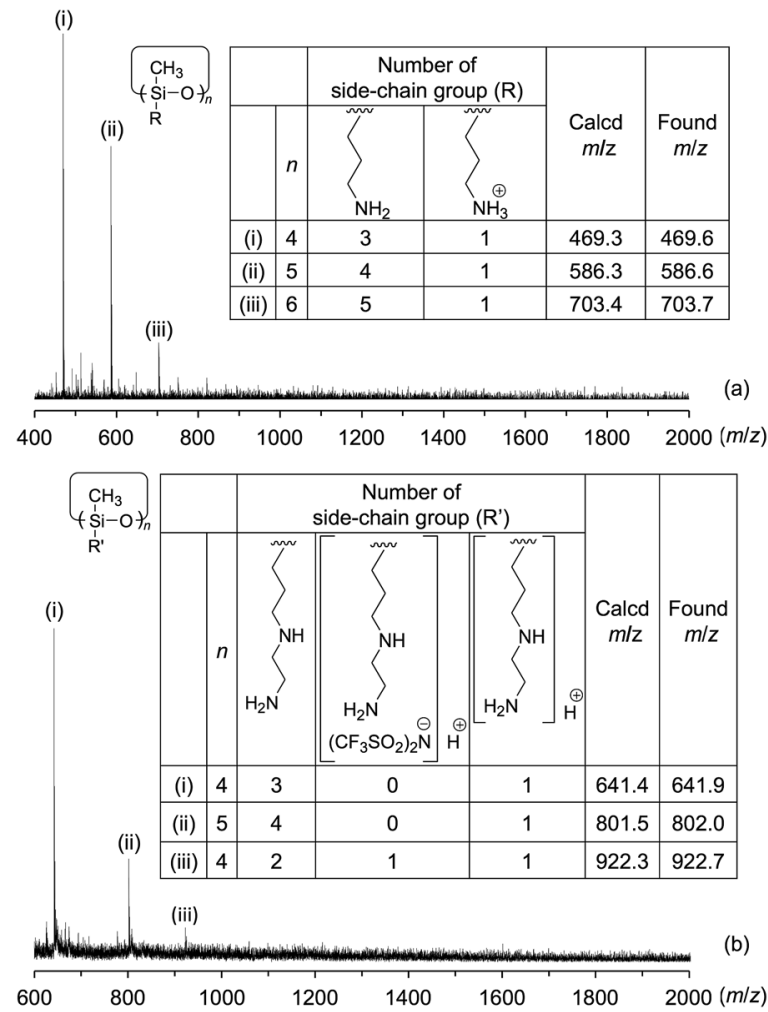

Fig. 3 MALDI-TOF MS of (a) Am-CyS-IL and (b) 2Am-CyS-IL.

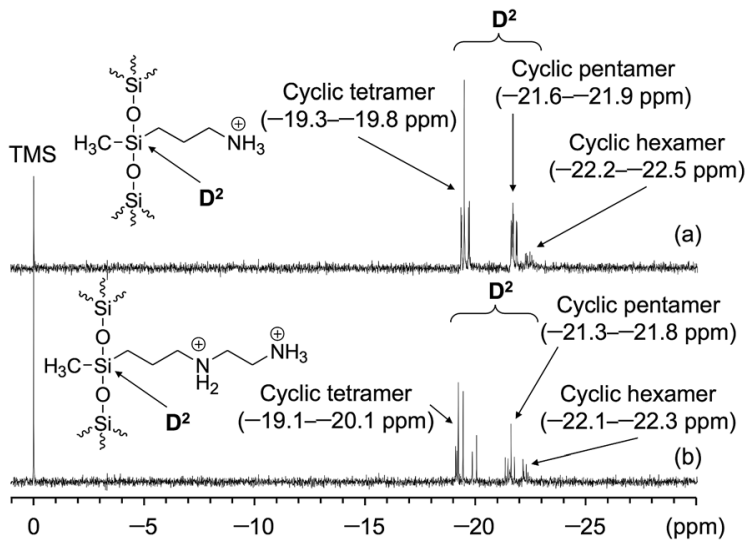

Fig. $4{ }^{29} \mathrm{Si}$ NMR spectra of (a) Am-CyS-IL and (b) $2 \mathrm{Am}-\mathrm{CyS}-\mathrm{IL}$ in DMSO- $d_{6}$ at $40{ }^{\circ} \mathrm{C}$. Chemical shifts were referenced to tetramethylsilane (TMS; $\delta$ 0.0).

another organodialkoxysilane containing two amino groups, AEAPDMMS, as a starting material (Scheme 1b). 2Am-CyS-IL was soluble in high-polarity solvents, such as water, methanol and acetone, but insoluble in low-polarity solvents, such as chloroform, toluene and hexane.

The ${ }^{1} \mathrm{H}$ NMR (Fig. 1b) and EDX (Fig. 2b) results of 2Am-CySIL indicated that the AEAPDMMS reagent was not present in the product, and that the molar ratio of ammonium cations to $\mathrm{NTf}_{2}$ anions in 2Am-CyS-IL was ca. $1: 1$. The MALDI-TOF MS results indicated the existence of a mixture of cyclic siloxane tetramer

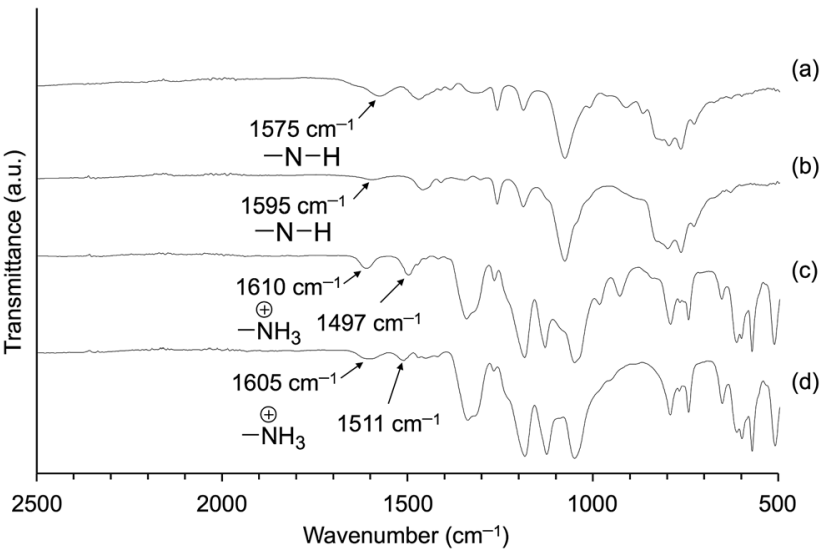

Fig. 5 ATR-IR spectra of (a) APDMMS, (b) AEAPDMMS, (c) Am-CyS-IL and (d) $2 A m-C y S-I L$.

and pentamer (Fig. 3b). Furthermore, the ${ }^{29} \mathrm{Si}$ NMR spectrum of 2Am-CyS-IL showed three multiple signals in the $\mathrm{D}^{2}$ region $(-19.1$ to $-20.1 \mathrm{ppm}$ for cyclic tetrasiloxane, -21.3 to $-21.8 \mathrm{ppm}$ for cyclic pentasiloxane, and -22.1 to $-22.4 \mathrm{ppm}$ for cyclic hexasiloxane) and no signals in the $\mathrm{D}^{1}$ region at $c a$. -15 ppm (Fig. 4b), supporting the formation of cyclic siloxanes. In addition, these compounds had some stereoisomers, as demonstrated by the ${ }^{1} \mathrm{H}$ NMR spectrum with multiple signals, a, due to the methyl groups at 0.27 to -0.01 ppm (Fig. 1b) and the ${ }^{29} \mathrm{Si}$ NMR spectrum with three multiple signals, as described above (Fig. 4b).

To confirm the formation of ionic pairs of the resulting products (Am-CyS-IL and 2Am-CyS-IL), we compared the ATR-IR spectra of these products and their starting materials (APDMMS and AEAPDMMS). The IR spectra of APDMMS and AEAPDMMS showed absorption peaks attributable to the bending vibration of amino groups at 1575 and $1595 \mathrm{~cm}^{-1}$, respectively (Fig. 5a and b). Conversely, those of Am-CyS-IL and 2Am-CyS-IL exhibited two typical absorption peaks attributable to the bending vibration of ammonium cations at 1610 and $1497 \mathrm{~cm}^{-1}$ for Am-CyS-IL (Fig. 5c) and at 1605 and $1511 \mathrm{~cm}^{-1}$ for 2Am-CySIL (Fig. 5d). In addition, these spectra did not exhibit absorption peaks due to the bending vibration of amino groups. Therefore, we concluded that cationic species (ammonium cations) were included in Am-CyS-IL and 2Am-CyS-IL. Meanwhile, because the $\mathrm{NTf}_{2}$ anion is extremely stable, $\mathrm{NTf}_{2}$ must be present as the anionic species in these compounds.

\section{Thermal properties of Am-CyS-IL and 2Am-CyS-IL}

The DSC analyses of Am-CyS-IL and 2Am-CyS-IL were performed at a heating rate of $20{ }^{\circ} \mathrm{C} \mathrm{min}{ }^{-1}$ under a nitrogen flow $(50 \mathrm{~mL}$ $\left.\min ^{-1}\right)$. The baseline shifts assigned to $T_{\mathrm{g}}$ were observed at $-2{ }^{\circ} \mathrm{C}$ for Am-CyS-IL (Fig. 6a) and at $9{ }^{\circ} \mathrm{C}$ for 2Am-CyS-IL (Fig. 6b). Conversely, endothermic peaks due to $T_{\mathrm{m}}$ were not detected for both compounds (Fig. 6a and b), indicating that Am-CyS-IL and 2Am-CyS-IL were amorphous compounds. In addition, sharp diffraction peaks were not observed in the XRD 


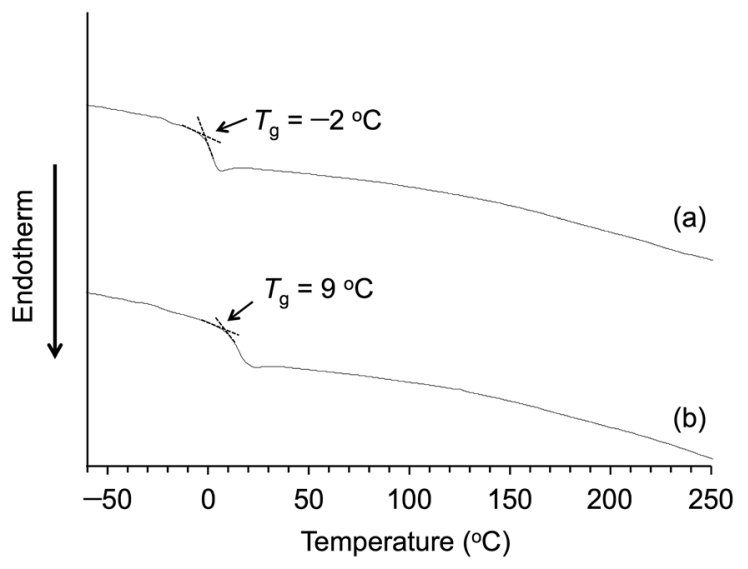

Fig. 6 DSC curves of (a) Am-CyS-IL and (b) 2Am-CyS-IL under a nitrogen flow.
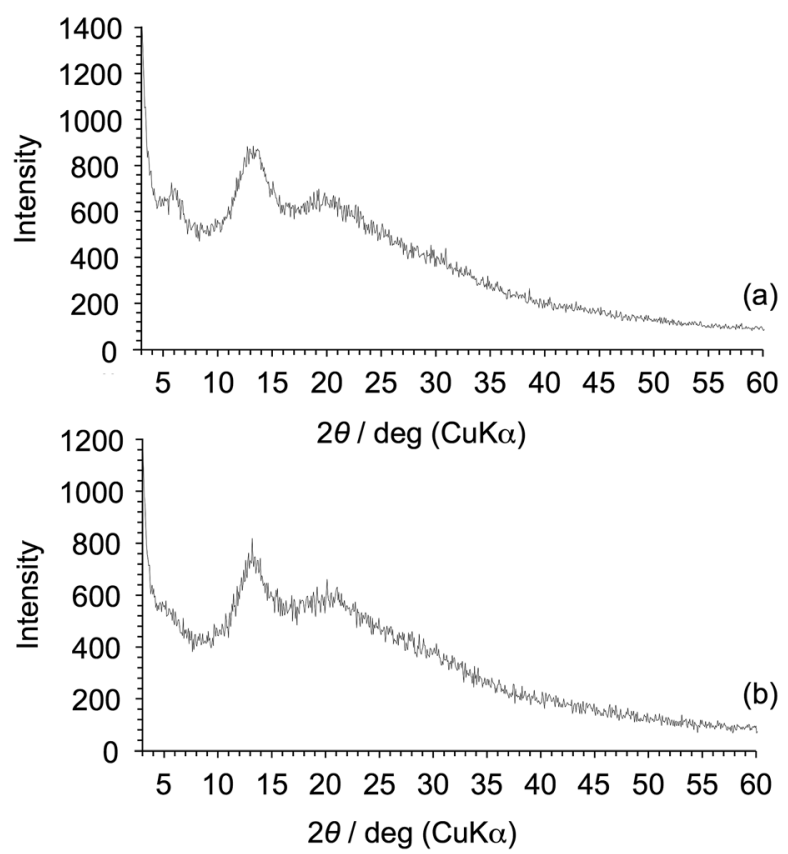

Fig. 7 XRD patterns of (a) Am-CyS-IL and (b) 2Am-CyS-IL. The amount of each product on the glass was ca. $1.0 \mathrm{mg} \mathrm{cm}^{-2}$.

patterns of Am-CyS-IL and 2Am-CyS-IL (Fig. 7a and b), supporting their amorphous or poorly crystalline structures.

The flow temperatures of Am-CyS-IL and 2Am-CyS-IL were confirmed as follows. Samples in glass vessels were maintained in a horizontal position at $150{ }^{\circ} \mathrm{C}$ for $15 \mathrm{~min}$, and then the vessels were cooled to room temperature, still in the horizontal position. Next, the vessels were maintained in a horizontal position at various temperatures (varied in $5{ }^{\circ} \mathrm{C}$ intervals) for $15 \mathrm{~min}$, and then held for $15 \mathrm{~min}$ while tilting at each temperature. During this procedure, Am-CyS-IL and 2Am-CyS-IL showed obvious fluidity at $\sim 35^{\circ} \mathrm{C}$ (Fig. 8 a) and $\sim 45^{\circ} \mathrm{C}$ (Fig. 8 b), respectively. On the basis of these results, we concluded that Am-CyS-IL and 2Am-CyS-IL were PILs.

To investigate the amount of water in these PILs, the weight losses at $150{ }^{\circ} \mathrm{C}$ were evaluated by TGA (Fig. 9a and b). (a)
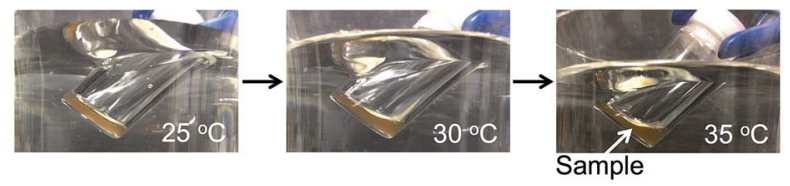

(b)

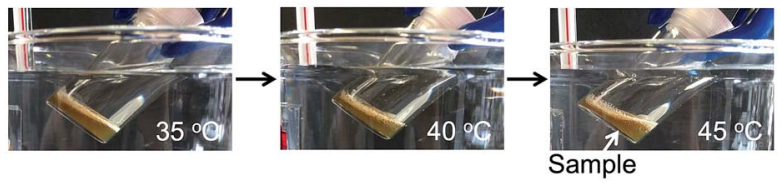

Fig. 8 Photographs of (a) Am-CyS-IL and (b) 2Am-CyS-IL at various temperatures.

Consequently, these values were $1.1 \%$ for Am-CyS-IL and $0.3 \%$ for 2Am-CyS-IL, indicating that these PILs contain a little moisture. However, because these samples were dried at $150{ }^{\circ} \mathrm{C}$ for $10 \mathrm{~h}$ after synthesis, it is presumed that they slightly absorbed moisture in the environment.

The thermal stabilities of Am-CyS-IL and 2Am-CyS-IL against pyrolysis were investigated by TGA at a heating rate of $10{ }^{\circ} \mathrm{C}$ $\min ^{-1}$ up to $1000^{\circ} \mathrm{C}$ under a nitrogen flow $\left(250 \mathrm{~mL} \mathrm{~min}^{-1}\right)$. The $T_{\mathrm{d} 5}$ and $T_{\mathrm{d} 10}$ values were 351 and $362{ }^{\circ} \mathrm{C}$, respectively, for AmCyS-IL (Fig. 9a). These values were higher than those of the propylamine- $\mathrm{NTf}_{2}$ salt $\left(281\right.$ and $\left.295^{\circ} \mathrm{C}\right)$, having the side-chain structure of Am-CyS-IL, with a $T_{\mathrm{g}}$ of $-65{ }^{\circ} \mathrm{C}$ and a $T_{\mathrm{m}}$ of $28{ }^{\circ} \mathrm{C}$ (Fig. 9c). These results indicate that the thermal stability of AmCyS-IL was enhanced by the incorporation of the cyclic oligosiloxane frameworks. The cyclic oligosiloxane frameworks could suppress molecular tumbling, resulting in the prevention of degradation. ${ }^{9}$ On the other hand, the $T_{\mathrm{d} 5}$ and $T_{\mathrm{d} 10}$ values of 2Am-CyS-IL were 294 and $309^{\circ} \mathrm{C}$ (Fig. 9b), which are almost the same as those of the $N$-propylethylenediamine-NTf 2 salt (299 and $309^{\circ} \mathrm{C}$ ), having the side-chain structure of $2 \mathrm{Am}$-CyS-IL, with a $T_{\mathrm{g}}$ of $-29^{\circ} \mathrm{C}$ and a $T_{\mathrm{m}}$ of $85^{\circ} \mathrm{C}$ (Fig. 9d). Because the side-chain groups of 2Am-CyS-IL are long, the suppression of molecular tumbling would not work. The weights of the residues of AmCyS-IL (ca. 12\%; Fig. 9a) and 2Am-CyS-IL (ca. 10\%; Fig. 9b) at $900{ }^{\circ} \mathrm{C}$ were almost the same as the theoretical $\mathrm{SiO}_{2}$ yields $(15 \%$ and $8 \%$, respectively).

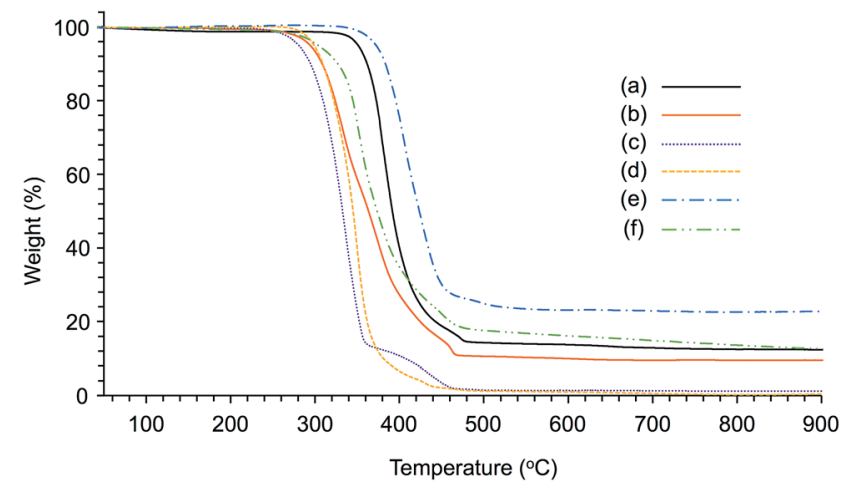

Fig. 9 TGA thermograms of (a) Am-CyS-IL, (b) 2Am-CyS-IL, (c) propylamine- $\mathrm{NTf}_{2}$ salt, (d) N-propylethylenediamine-NTf 2 salt, (e) AmPOSS and (f) 2Am-POSS under a nitrogen flow. 


\section{Influence of structures of siloxane frameworks on IL nature}

To investigate the influence of the structures of the siloxane frameworks on the nature of the ILs, we prepared POSS compounds containing the same side-chain groups and counteranions (Am-POSS and 2Am-POSS). In our previous studies, POSS compounds containing ammonium side-chain groups were prepared by the hydrolytic condensation of APTMS, ${ }^{17}$ AEAPTMS $^{18}$ and an APTMS/AEAPTMS mixture ${ }^{18}$ using aqueous superacid HOTf. Therefore, to obtain POSS compounds containing the same counteranions as Am-CyS-IL and 2Am-CyS-IL, the hydrolytic condensation of APTMS and AEAPTMS was performed using $\mathrm{HNTf}_{2}$ as a catalyst, respectively (Scheme 2).

POSSs with one ammonium group (Am-POSS) and two ammonium groups (2Am-POSS) per repeating unit were prepared according to the following procedure (Scheme 2): APTMS and AEAPTMS were stirred in $0.5 \mathrm{~mol} \mathrm{~L}^{-1}$ aqueous $\mathrm{HNTf}_{2}$ solutions at room temperature for $2 \mathrm{~h}$, respectively. Here, excess amounts of $\mathrm{HNTf}_{2}$ were required (feed molar ratio of $\mathrm{HNTf}_{2}$ /amino group was 2.5). The subsequent procedures were the same as those described above for the preparation of AmCyS-IL and 2Am-CyS-IL.

Characterization of Am-POSS and 2Am-POSS was performed using ${ }^{1} \mathrm{H}$ NMR (Fig. 10), EDX (Fig. 11) and ${ }^{29} \mathrm{Si}$ NMR (Fig. 12) measurements. Especially, the ${ }^{29} \mathrm{Si}$ NMR results



(a) 3-Aminopropyltrimethoxysilane
(APTMS) $(\mathrm{R}=-\mathrm{H})$

(b) 3-(2-Aminoethylamino)propyltrimethoxysilane (AEAPTMS) $\left(\mathrm{R}=-\left(\mathrm{CH}_{2}\right)_{2} \mathrm{NH}_{2}\right)$

$\mathrm{T}_{8}$-POSS (Main product) $\quad \mathrm{T}_{10}$-POSS (Minor product)

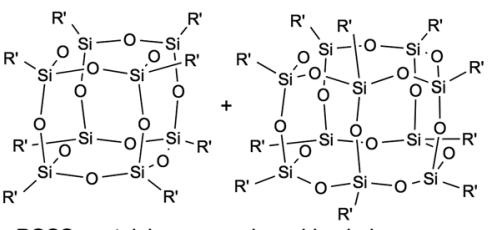

POSS containing ammonium side-chain groups and $\mathrm{NTf}_{2}$ counteranions

(a) Am-POSs $\left(\mathrm{R}^{\prime}=-\left(\mathrm{CH}_{2}\right)_{3} \stackrel{\oplus}{\mathrm{N}} \mathrm{H}_{3} \cdot\left(\mathrm{CF}_{3} \mathrm{SO}_{2}\right)_{2} \stackrel{\ominus}{\mathrm{N}}\right)$

(b) 2Am-POSS $\left(\begin{array}{r}\mathrm{R}^{\prime}=-\left(\mathrm{CH}_{2}\right)_{3} \stackrel{\oplus}{\mathrm{N}} \mathrm{H}_{2}\left(\mathrm{CH}_{2}\right)_{2} \stackrel{\oplus}{\mathrm{N}} \mathrm{H}_{3} \\ 2\left[\left(\mathrm{CF}_{3} \mathrm{SO}_{2}\right)_{2} \mathrm{~N}\right]\end{array}\right)$

Scheme 2 Preparation of POSSs containing ammonium side-chain groups and $\mathrm{NTf}_{2}$ counteranions: (a) Am-POSS and (b) 2Am-POSS.

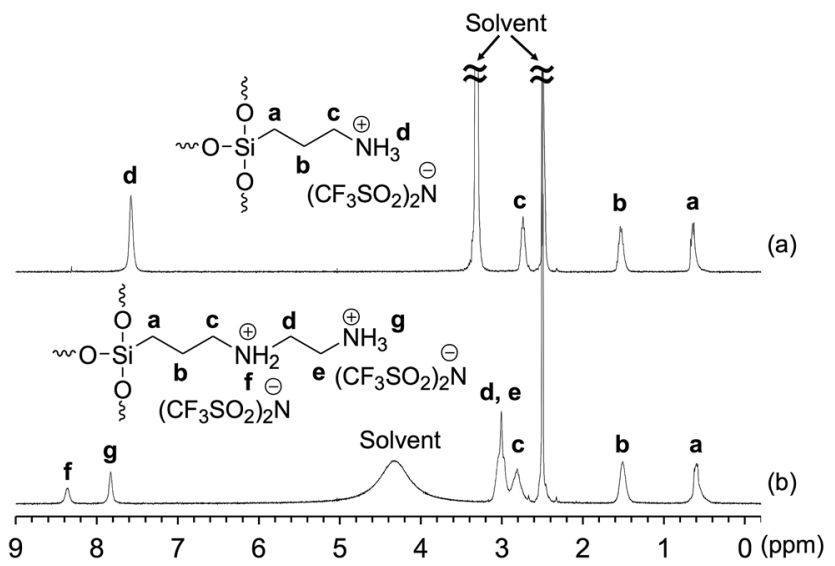

Fig. $10{ }^{1} \mathrm{H}$ NMR spectra of (a) Am-POSS and (b) 2Am-POSS in DMSO$d_{6}$. Chemical shifts were referenced to DMSO $(\delta 2.5)$.

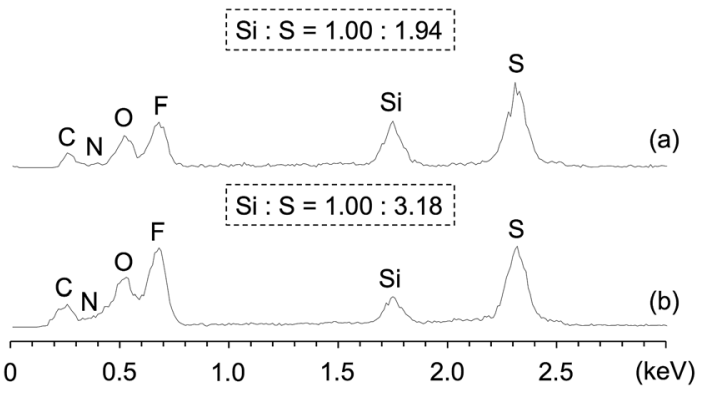

Fig. 11 EDX patterns of (a) Am-POSS and (b) 2Am-POSS.

indicated that these compounds were mixtures of cage-like octasilsesquioxane ( $\mathrm{T}_{8}$-POSS) and cage-like decasilsesquioxane ( $\mathrm{T}_{10}$-POSS) (Fig. 12). However, the molar ratio of ammonium cations to $\mathrm{NTf}_{2}$ anions in 2Am-POSS was ca. $1: 0.79$, i.e. a non-equimolar ratio (Fig. 11b). This is probably because it is difficult for $\mathrm{HNTf}_{2}$ to approach the amino side-chain groups in 2Am-POSS due to their bulky nature.

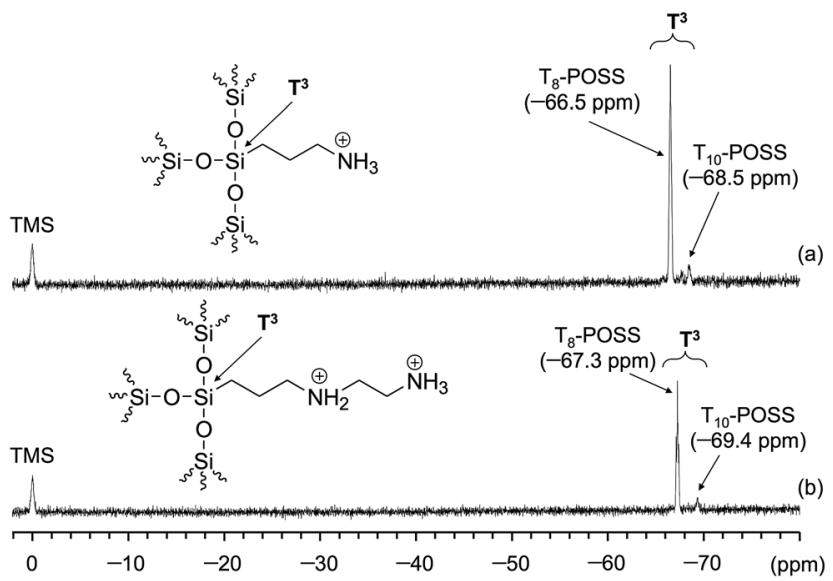

Fig. $12{ }^{29} \mathrm{Si}$ NMR spectra of (a) Am-POSS and (b) $2 \mathrm{Am}$-POSS in DMSO $-d_{6}$ at $40{ }^{\circ} \mathrm{C}$. Chemical shifts were referenced to TMS $(\delta 0.0)$.

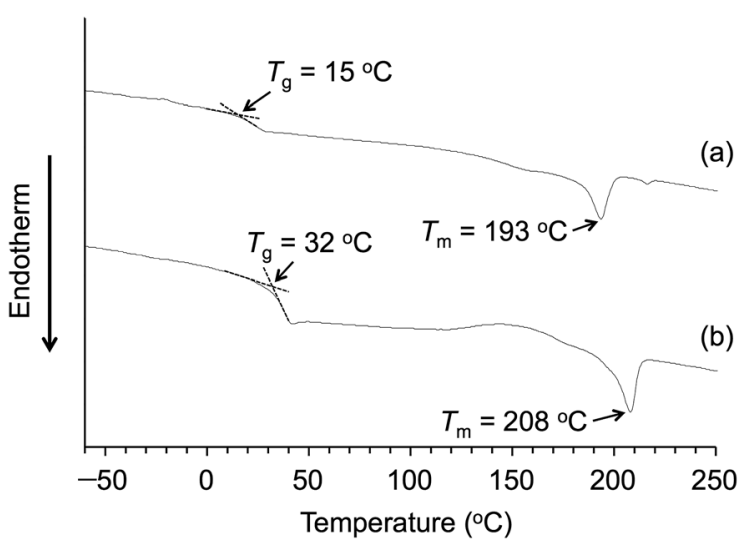

Fig. 13 DSC curves of (a) Am-POSS and (b) 2Am-POSS under a nitrogen flow. 
The DSC curve of Am-POSS showed a baseline shift due to $T_{\mathrm{g}}$ at $15{ }^{\circ} \mathrm{C}$ and an endothermic peak due to $T_{\mathrm{m}}$ at $193{ }^{\circ} \mathrm{C}$ (Fig. 13a). In addition, the XRD pattern of Am-POSS showed several sharp diffraction peaks (Fig. 14a), indicating that Am-POSS was a crystalline compound. Furthermore, this POSS compound did not exhibit fluidity at $150{ }^{\circ} \mathrm{C}$ (Fig. 15a), indicating that it was not an IL. On the other hand, the DSC curve of 2Am-POSS exhibited a baseline shift due to $T_{\mathrm{g}}$ at $32{ }^{\circ} \mathrm{C}$ and an endothermic peak due to $T_{\mathrm{m}}$ at $208{ }^{\circ} \mathrm{C}$ (Fig. 13b). Additionally, the XRD pattern of $2 \mathrm{Am}$ POSS also supported the formation of a crystalline structure, i.e. several sharp diffraction peaks were detected (Fig. 14b). Furthermore, this compound did not show fluidity at $150{ }^{\circ} \mathrm{C}$ (Fig. 15b). Based on these results, we concluded that the cyclic oligosiloxane frameworks with flexible structures compared with POSS are important for the preparation of siloxane-based PILs exhibiting fluidity at low temperature.

Incidentally, Am-POSS and 2Am-POSS exhibited high thermal stabilities in the TGA analyses. The $T_{\mathrm{d} 5}$ and $T_{\mathrm{d} 10}$ values
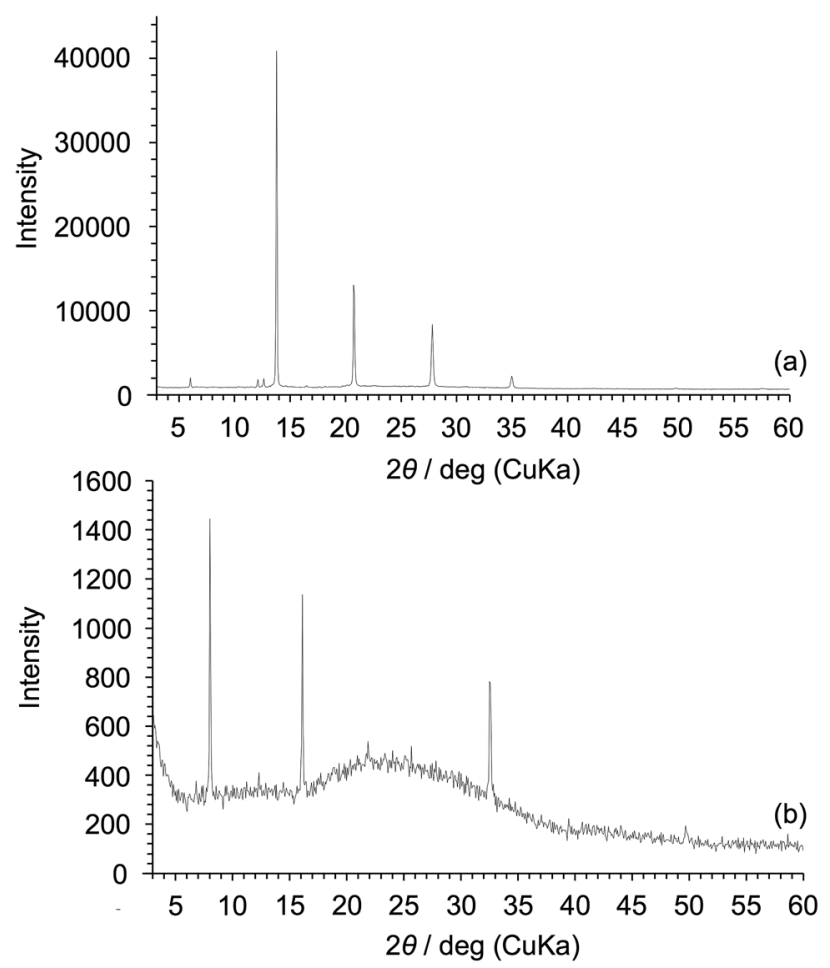

Fig. 14 XRD patterns of (a) Am-POSS and (b) 2Am-POSS. The amount of each product on the glass was ca. $1.0 \mathrm{mg} \mathrm{cm}^{-2}$. (a)

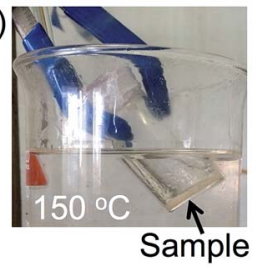

(b)

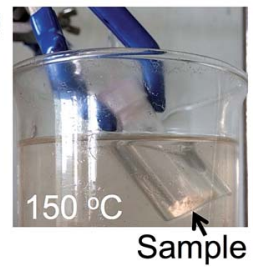

Fig. 15 Photographs of (a) Am-POSS and (b) 2Am-POSS at $150^{\circ} \mathrm{C}$. were 372 and $384{ }^{\circ} \mathrm{C}$ for Am-POSS (Fig. 9e) and 304 and $327^{\circ} \mathrm{C}$ for 2Am-POSS (Fig. 9f).

\section{Conclusions}

In this study, we found that PILs containing cyclic oligosiloxane frameworks, Am-CyS-IL and 2Am-CyS-IL, could be successfully prepared by the hydrolytic condensation of APDMMS and AEAPDMMS using a water/methanol (1:19 v/v) mixed solution of $\mathrm{HNTf}_{2}$. The DSC curves of Am-CyS-IL and 2Am-CyS-IL exhibited baseline shifts attributable to $T_{\mathrm{g}}$ at $-2{ }^{\circ} \mathrm{C}$ and $9{ }^{\circ} \mathrm{C}$, respectively, and endothermic peaks at $T_{\mathrm{m}}$ were not detected for both compounds, indicating their amorphous structures. In addition, fluidity was visually observed for each compound at $\sim 35{ }^{\circ} \mathrm{C}$ and $\sim 45^{\circ} \mathrm{C}$, respectively, indicating that Am-CyS-IL and 2Am-CyS-IL were PILs. For comparison, POSSs containing the same side-chain groups and counteranions, Am-POSS and 2AmPOSS, were prepared from APTMS and AEAPTMS, respectively, using an $\mathrm{HNTf}_{2}$ catalyst. Am-POSS had $T_{\mathrm{g}}$ of $15{ }^{\circ} \mathrm{C}$ and $T_{\mathrm{m}}$ of $193{ }^{\circ} \mathrm{C}$, and 2Am-POSS had $T_{\mathrm{g}}$ of $32{ }^{\circ} \mathrm{C}$ and $T_{\mathrm{m}}$ of $208{ }^{\circ} \mathrm{C}$. Furthermore, fluidity was not observed below $150{ }^{\circ} \mathrm{C}$ for either compound, indicating that these POSS compounds were not PILs. These results suggest that the cyclic oligosiloxane frameworks are an important factor for the preparation of siloxanebased PILs exhibiting fluidity at low temperature. The present PILs containing cyclic oligosiloxane frameworks exhibited relatively high thermal stabilities (Am-CyS-IL: $T_{\mathrm{d} 5}=351{ }^{\circ} \mathrm{C}$ and $T_{\mathrm{d} 10}=362{ }^{\circ} \mathrm{C}$, 2Am-CyS-IL: $T_{\mathrm{d} 5}=294{ }^{\circ} \mathrm{C}$ and $T_{\mathrm{d} 10}=309^{\circ} \mathrm{C}$ ).

\section{Acknowledgements}

We acknowledge the support of Prof. Y. Suda, Dr M. Wakao and Dr H. Shinchi of the Graduate School of Science and Engineering, Kagoshima University (Japan) in MALDI-TOF MS measurements. This work was supported by JSPS KAKENHI (Grant-in-Aid for Challenging Exploratory Research) Number $15 \mathrm{~K} 13711$.

\section{References and Notes}

1 T. L. Greaves and C. J. Drummond, Chem. Rev., 2008, 108, 206.

2 T. L. Greaves and C. J. Drummond, Chem. Rev., 2015, 115, 11379.

3 S. Y. Lee, A. Ogawa, M. Kanno, H. Nakamoto, T. Yasuda and M. Watanabe, J. Am. Chem. Soc., 2010, 132, 9764.

4 S. Menne, J. Pires, M. Anouti and A. Balducci, Electrochem. Commun., 2013, 31, 39.

5 L. Mayrand-Provencher, S. Lin, D. Lazzerini and D. Rochefort, J. Power Sources, 2010, 195, 5114.

6 E. C. Achinivu, R. M. Howard, G. Li, H. Gracz and W. A. Henderson, Green Chem., 2014, 16, 1114.

7 R. Vijayraghavan, S. J. Pas, E. I. Izgorodina and D. R. MacFarlane, Phys. Chem. Chem. Phys., 2013, 15, 19994.

8 T. J. Simons, T. Verheyen, E. I. Izgorodina, R. Vijayaraghavan, S. Young, A. K. Pearson, S. J. Pas and D. R. MacFarlane, Phys. Chem. Chem. Phys., 2016, 18, 1140. 
9 K. Tanaka, F. Ishiguro and Y. Chujo, J. Am. Chem. Soc., 2010, 132, 17649.

10 J. Tan, D. Ma, X. Sun, S. Feng and C. Zhang, Dalton Trans., 2013, 42, 4337.

11 T. Ishii, T. Enoki, T. Mizumo, J. Ohshita and Y. Kaneko, RSC Adv., 2015, 5, 15226.

12 T. Ishii, T. Mizumo and Y. Kaneko, Bull. Chem. Soc. Jpn., 2014, 87, 155.

13 A. Harada, S. Koge, J. Ohshita and Y. Kaneko, Bull. Chem. Soc. Jpn., 2016, 89, 1129.
14 T. Kubo, S. Koge, J. Ohshita and Y. Kaneko, Chem. Lett., 2015, 44, 1362.

15 S. Kinoshita, S. Watase, K. Matsukawa and Y. Kaneko, J. Am. Chem. Soc., 2015, 137, 5061.

16 Y. R. Mirzaei, B. Twamley and J. M. Shreeve, J. Org. Chem., 2002, 67, 9340.

17 Y. Kaneko, M. Shoiriki and T. Mizumo, J. Mater. Chem., 2012, 22, 14475.

18 T. Tokunaga, M. Shoiriki, T. Mizumo and Y. Kaneko, J. Mater. Chem. C, 2014, 2, 2496. 